\title{
Aspekte van sintaktiese inligting in verklarende Afrikaanse woordeboeke
}

\author{
W.F. Botha, Buro van die Woordeboek van die Afrikaanse Taal, \\ Stellenbosch, Suid-Afrika
}

\begin{abstract}
Aspects of syntactic information in descriptive Afrikaans dictionaries. Syntactic information is not presented in a consistent manner in the articles of lexical and multilexical lemmas in descriptive Afrikaans dictionaries. New terminology and information resulting from linglistic research are seldom portrayed. Three slots for syntactic information in the article of a lemma are suggested: a slot for a lexical item classification, a slot for information on the typical syntactic behaviour of a lemma and a third slot for usage examples in which explicit information on non-typical syntactic behaviour is provided. Ways are suggested for the presentation of syntactic information in the articles of multilexical lemmas. Practical proposals are made for the reflection of new termunology and information resulting from linguistic research.
\end{abstract}

Keywords: ADJUNCT, FIXED EXPRESSIONS, LEXICAL ITEM CLASSIFICATION, LOANWORD PHRASES, MULTILEXICAL LEMMAS, NON-TYPICAL SYNTACTIC BEHAVIOUR, PREPOSITIONAL PHRASES, SYNTACTIC INFORMATION, TYPICAL SYNTACTIC BEHAVIOUR

Opsomming: Sintaktiese inligting in verklarende Afrikaanse woordeboeke word nie op konsekwente wyse by leksikale en multileksikale lemmas aangebied nie en nuwe terminologie en inligting uit die teoretiese taalkunde word selde weerspieël. Drie gleuwe vir sintaktiese inligting in die artikel van 'n lemma word voorgestel: 'n gleuf vir 'n leksikale-itemklassifikasie, 'n gleuf vir inligting omtrent die tipiese sintaktiese optrede van 'n lemra en 'n derde gleuf vir voorbeeldmateriaal waarin ook eksplisiete inligting omtrent atipiese sintaktiese optrede verskaf word. Voorstelle word gemaak vir die aangawe van sintaktiese inligting in die artikels van multileksikale lemmas. Daar word ook gekyk na praktiese oplossings vir die weerspieëling van nuwe inligting en terminologie uit die teoretiese taalkunde.

Sleutelwoorde: ADJUNK, ATIPIESE SINTAKTIESE OPTREDE, GROEPSETSELS, LEENWOORDGROEPE, LEKSIKALE-ITEMKLASSIFIKASIE, MULTILEKSIKALE LEMMAS, SINTAKTIESE INLIGTING, TIPIESE SINTAKTIESE OPTREDE, UITDRUKKINGS 


\section{Inleidend}

Verklarende woordeboeke behoort die leksikon op só 'n wyse aan te bied dat al die verskillende inligtingstipes tot hul reg kom. Alhoewel die semantiese altyd die komponent sal wees waaraan die meeste aandag bestee word, behoort die sintaktiese komponent nou daarmee geïntegreer te wees. Zgusta (1971: 265) beklemtoon dat sintaktiese inligting ' $n$ wesenlike deel van 'n woordeboek moet wees en nie hanteer moet word asof dit 'n soort nagedagte is nie.

Tussen die semantiese en die sintaktiese komponent bestaan daar 'n noue verband omdat leksikale items nie in isolasie funksioneer nie, maar in sinsverband. Die gebruiker moet derhalwe van voldoende sintaktiese inligting voorsien word om self die item in sinsverband te kan gebruik. Gouws (1989: 229) wys daarop dat tipiese asook problematiese aspekte van die lemma se optrede in sinsverband toegelig moet word.

In hierdie artikel word voorstelle gemaak rondom die eksplisiete en implisiete aanbieding van sintaktiese inligting by leksikale en multileksikale lemmas in verklarende Afrikaanse woordeboeke. Die artikel is gerig op 'n praktiese oplossing en is nie in die eerste plek op die teorie ingestel nie.

\section{Gleuwe vir verskillende tipes sintaktiese inligting}

Dit sou nadelig vir die gebruiksvriendelikheid van 'n woordeboekartikel wees indien verskillende tipes sintaktiese inligting gesamentlik in 'n bepaalde gleuf verskaf word. Anders as bv. morfologiese inligting is sintaktiese inligting van 'n geskakeerde aard en kan dit in die artikel versprei word. Hieronder volg 'n uiteensetting vir die aanbieding van sintaktiese inligting in drie verskillende gleuwe. In die eerste gleuf word 'n leksikale-iłemklassifikasie verskaf, bv. werkwoord, groepsetsel of uitdrukking. Die tweede gleuf bevat inligting omtrent die tipiese sintaktiese optrede van 'n lemma, bv. die vaste voorsetselverbinding van sekere werkwoorde (voorsien van). In die derde gleuf word voorbeeldmateriaal aangebied en met behulp van subgleuwe word ook bykomende inligting omtrent problematiese of atipiese sintaktiese optrede verskaf.

Omdat die gleuf vir 'n leksikale-itemklassifikasie die mees problematiese is, word veral dáárop gekonsentreer. Die gleuwe vir tipiese en atipiese sintaktiese inligting is relatief probleemloos en daarom word volstaan met enkele voorbeelde.

\section{$2.1 \quad$ Leksikale-itemklassifikasie}

Lemmas word in verklarende Afrikaanse woordeboeke tradisioneel van in woordsoortklassifikasie voorsien. Dit volg gewoonlik onmiddellik ná die lemmagleuf. Die vernaamste kritiek teen die heersende praktyk is dat slegs 
leksikale lemmas so 'n klassifikasie kan ontvang en dat van verouderde klassifikasieterme gebruik gemaak word (Gouws 1989: 213). Wat hier volg, is 'n poging om na aanleiding van hierdie en ander kritiek 'n beter leksikografiese praktyk rondom die klassifisering van leksikale items daar te stel.

\subsubsection{Leksikale lemmas}

Drie klassifikasieterme word vervolgens bespreek, nl. dié van werkwoord, byvoeglike naamwoord en bywoord.

\section{Die klassifikasie van werkwoorde}

Woordeboeke volstaan gewoonlik met 'n primêre klassifikasie van leksikale items as werkwoorde:

$$
\text { lyk ww. ... (Nasionale Woordeboek (hierna NW)) }
$$

Teoretici (Gouws 1989: 223, Otto 1989: 80 e.v.) is ten gunste van die verfyning van woordsoortaanduiding deur middel van 'n sekondêre klassifikasie. Ponelis (1979: 187) onderskei twee hoofklasse werkwoorde: hoofwerkwoorde en medewerkwoorde. Die hoofwerkwoorde sluit oorganklike, onoorganklike, koppel-, voorsetsel-, wederkerende en deeltjiewerkwoorde in. Medewerkwoorde word verdeel in die subkategorieë hulpwerkwoorde en skakelwerkwoorde.

Kom en laat soos gebruik in die verbindings kom kuier en laat hoor is voorbeelde van skakelwerkwoorde. NW en die Woordeboek van die Afrikaanse Taal (hierna WAT) maak wel in hul artikels van kom gebruik van 'n sekondêre klassifikasie. Beide gee 'n primêre klassifikasie as werkwoord en verstrek dan by ' $n$ bepaalde betekenisonderskeiding 'n sekondêre klassifisering:

kom. I w....

2. (as hulpw.) ... (WAT)

kom II ww....

8. as hulpww. van aspek ... (NW)

Deur kom as hulpwerkwoord te klassifiseer in 'n bepaalde betekenisonderskeiding, word te kenne gegee dat dit ook as 'n nieselfstandige werkwoord kan optree. Alhoewel die klassifisering nie aansluit by die heersende taalkundige terminologie nie, word die gebruiker wel van inligting voorsien omtrent die nieselfstandige optrede van kom.

NW maak geen werklike sekondêre klassifikasie in die geval van laat nie, maar volg tog 'n sekere prosedure ter aanduiding van 'n onderskeidende optrede van die woord in 'n sekere betekenisonderșeiding: 
laat. 1 ww....

6. veroorsaak, doen, maak dat iets gebeur. Iem. laat weet, haal, roep.

Opmerking: Daar is 'n algehele teenstelling tussen betekenis 6 en die voorafgaande betekenisse. (NW)

NW gaan hier op ' $n$ totaal inkonsekwente wyse te werk in die beskrywing van kom en laat, aangesien kom wel van 'n subklassifikasie voorsien word, maar daar net op 'n vae wyse d.m.v. 'n opmerking gewys word op die nieselfstandige optrede van laat. Soos vervolgens getoon sal word, kan die gebruik van 'n opmerking egter wel verhelderend wees.

Dit lyk nie asof die terme medewerkwoord, skakelwerkwoord of deeltjiewerkwoord al in so 'n mate tot die omgangstaal deurgedring het dat aanvaar kan word dat dit aan die meeste woordeboekgebruikers bekend is nie. Nie een van Suid-Afrika se onderwysdepartemente maak bv. voorsiening vir dié terme in hul Afrikaans-leerplanne nie.

Die woordeboekmaker is dus huiwerig om die nuwe terme te gebruik. Dit blyk opnuut uit die feit dat die 1993-uitgawe van die Verklarende Afrikaanse Woordeboek (hierna VAW) geen vernuwing t.o.v. woordsoortterminologie bevat nie. Dit is ' $n$ jammerte, want dit is by uitstek die handwoordeboeke wat die weg moet baan vir vernuwing. Handwoordeboeke word elke 5 tot 10 jaar hersien, wat 'n uitstekende geleentheid vir vernuwing in terminologie bied. 'n Omvattende woordeboek soos die WAT is nie in dieselfde posisie nie aangesien daar ter wille van kontinuiteit deurlopend van dieselfde terminologie gebruik gemaak moet word.

Die feit dat die 1991-uitgawe van die Afrikaanse Woordelys en Spelreëls die terme deeltjiewerkwoord, medewerkwoord en skakelwerkwoord in die lys van terme insluit wat in die toeligting verklaar word, kan lei tot 'n breër bekendstelling daarvan.

Dit lê nie op die weg van die leksikograaf om terminologie te skep of bestaande terminologie te beoordeel nie - hy moet hom egter van terminologie bedien wat die stand van die taalkunde weerspieël terwyl hy tegelykertyd ook die woordeboekgebruikers se bekendheid met die terminologie in ag moet neem. Dit is derhalwe te betwyfel of dit tans wys is om op blatante wyse in sekondêre klassifikasie volgens die jongste terminologie te verskaf. Die belange van die woordeboekgebruiker sal waarskynlik beter gedien word deur 'n primêre klassifikasie aangevul deur 'n opmerking waarin 'n sekondêre klassifikasie verstrek word:

3laat ww. ...

OPM. Laat behoort tot die hoofgroep werkwoorde bekend as medewerkwoorde. Medewerkwoorde word verdeel in die subkategorieë hulpwerkwoorde en skakelwerkwoorde. Laat is 'n skakelwerkwoord. 


\section{Die klassifikasie van byvoeglike naamwoorde}

Sommige woordeboeke (bv. NW) klassifiseer leksikale items wat as naamwoordelike sowel as bywoordelike bepalings optree as byvoeglike naamwoorde, bv. mooi, vinnig, skelm. Ander (WAT, HAT, VAW) klassifiseer hierdie items as byvoeglike naamwoorde én bywoorde:

krom. I b.n. en bw., krommer, kromste. (WAT)

mooi2, (b, bw), (-e); -er, -ste. (VAW)

vinnig, b.nw. en bw. (HAT)

Skerp kritiek is reeds uitgespreek teen die klassifikasie van leksikale items as "b.nw. en bw." (Redaksie, Buro van die WAT 1989: 43-44). Daar is geredeneer dat verwarring geskep word tussen woordsoortkategorieë en meerfunksionaliteit deurdat "b.nw. en bw." die indruk skep van twee woordsoortelike kategorieë, terwyl hier eintlik sprake is van meerfunksionaliteit.

In die geval van die WAT is die verwarring volkome deurdat die aanloop "byw. gebruik" verwys na die meerfunksionele optrede van 'n leksikale item. Voorbeelde hiervan kom in die artikel van die lemma KRING binne die selfstandigenaamwoordkategorie voor:

kring1. I s. ... 1. a. ... I/d iteratiefvorm, byw. gebruik: Die maan op die water is in tallose visskoffies van silwer verbreek, om langsaam kring-kring ' $n$ drywende boog te herbou.

b. i. ... I/d mv. sonder die voors. in, byw. gebruik: Die roofooël draai kringe oor die swart tentlatte van die kakebeenwa.

Hierbenewens word daar ook in die WAT aangedui dat 'n item slégs byvoeglik optree deur dit as "b.n." te klassifiseer:

kortwerkend. b.n. ... 'n Kortwerkende verdowingsmiddel.

'n Bepaalde lemma kan ook in sekere betekenisonderskeidings slegs as b.nw. en in ander slegs as bw. optree:

kortliks. I bw....

II b.n.

(WAT)

Dit wil dus voorkom asof daar tog ruimte bestaan vir ' $n$.klassifikasie ter aanduiding daarvan dat sommige byvoeglike naamwoorde as bywoordelike bepalings optree en ander nie. Die klassifikasie moet egter geen ruimte laat vir verwarring tussen woordsoortkategorie en meerfunksionaliteit nie.

Die term adjunk (Ponelis 1979: 289, e.v.) is baie wyd en verwys na een van die hoofkomponente in ' $n$ stuk of sin. Dit sluit o.a. byvoeglike naamwoorde 
(gradeerbare adjunk in 'n naamwoord- of werkwoordstuk), bywoorde (niegradeerbare adjunk in 'n werkwoordstuk) en groepvoorsetsels (adjunk in 'n naamwoordstuk) in. Dit is derhalwe te wyd om as term te gebruik vir die bywoordelike optrede van 'n byvoeglike naamwoord soos reeds voorgestel is (Redaksie, Buro van die WAT 1989: 43).

'n Moontlike oplossing sou wees om byvoeglike naamwoord te gebruik waar 'n item slegs as naamwoordelike bepaling optree asook waar ' $n$ item as naamwoordelike én bywoordelike bepaling optree. In laasgenoemde geval kan die bywoordelike optrede egter soos in alle gevalle van meerfunksionaliteit uitgelig word deur middel van 'n aanloop:

mooi b.nw.; mooier, mooiste.

1 Aangenaam vir die sintuie: Die mooi meisie laat die manne se koppe draai.

- Ook bywoordelik: Die virtuoos speel só mooi viool dat selfs die honde luister.

- Ook soms selfstandig: Die mooi van die lewe. Die goeie is beter as die mooie.

Die voorgestelde hantering stel die leksikograaf in staat om voorbeeldmateriaal volgens die funksionele optrede van die betrokke leksikale item te verdeel. Sodoende word waardevolle inligting omtrent die sintaktiese optrede van die lemma aan die gebruiker verskaf.

\section{Die klassifikasie van bywoorde}

Die kategorie bywoord word deur verklarende Afrikaanse woordeboeke gebruik ten opsigte van niegradeerbare bywoordelike bepalings:

$\begin{array}{ll}\text { amper bw.... } & \text { (NW) } \\ \text { dikwels bw.... } & \text { (NW) } \\ \text { liefs bw.... } & \text { (NW) } \\ \text { blindweg bw.... } & \text { (NW) }\end{array}$

Die VAW verskaf slegs 'n woordsoortaanduiding by homonieme wat ten opsigte van woordsoortelikheid verskil:

$$
\begin{aligned}
& \operatorname{nou}^{1},(s) \\
& \operatorname{nou}^{2},(b) \\
& \operatorname{nou}^{3},(b w)
\end{aligned}
$$

wat meebring dat bywoorde soos amper en dikwels geen woordsoortaanduiding ontvang nie en die gebruiker meestal in die duister gelaat word ten opsigte van die woordsoortelikheid van lemmas. 
Die hantering van die meerfunksionele optrede van bywoorde in verklarende Afrikaanse woordeboeke is nie altyd bevredigend nie (vgl. die behandeling in die HAT van amper en dikwels). Indien daar sprake is van meerfunksionaliteit sonder gepaardgaande betekenisverskil kan die hanteringswyse wat hierbo voorgestel is, gevolg word:

landinwaarts bw. In die land in of na die binneland toe: Hy sien dat duisende seevoëls landinwaarts vlieg. Kleiner skepe kan taamlik ver landinwaarts vaar op die rivier.

- Ook byvoeglik: In die landinwaartse distrikte het ander bouvorms vir plaashuise ontwikkel.

dikwels bw. ...

- Ook soms byvoeglik: Die dikwelse gebruik van vlooipoeier word aanbeveel.

Indien die meerfunksionaliteit van 'n leksikale item gepaard gaan met betekenisverskil behoort verskillende woordsoortkategorieë gemaak te word:

lekker I b.nw., lekkerder, lekkerste.

1 Wat genot verskaf: 'n Lekker naweek, partytjie, vakansie.

- Ook bywoordelik: Lekker eet, drink, ontspan.

2 ...

II bw. Baie erg of in 'n hoë mate: Jy's darem lekker laf! Lekker moeg, dors, siek, bang wees. Ek het lekker geskrik toe ek hom sien.

III tw. ...

Die bywoord-karakter van lekker in bet. Il blyk onder meer daaruit dat dit nie gradeerbaar is nie. In die bywoordelike gebruik van die byvoeglike naamwoord in bet. I is lekker egter wel gradeerbaar.

\subsubsection{Multileksikale lemmas}

Omdat multileksikale leksikonitems selde gelemmatiseer word en meestal as mikrostruktuurelemente opgeneem word, is daar nie eintlik sprake van 'n leksikale-itemklassifikasie nie. NW neem bv. die uitdrukkings met wortel en tak uitroei, van die hak op die tak spring, hoog in die takke wees en die takke insit onder die eerste betekenisonderskeiding van die leksikale lemma tak op. HAT en WAT neem uitdrukkings in 'n rubriek in die artikel van 'n leksikale lemma op.

Alle multileksikale leksikonitems behoort as multileksikale lemmas opgeneem te word en van 'n leksikale-itemklassifikasie voorsien te word in die gleuf wat daarvoor gereserveer word.

In die metaleksikografie is reeds wyses aangedui waarop meerwoordige leksikale items gelemmatiseer kan word (vgl. Gouws 1990 en Botha 1991). 'n 
Metode van gemerkte lemmatisering waarvolgens multileksikale lemmas volgens bepaalde kernkomponente (wat lidwoorde, voorsetsels en voornaamwoorde uitsluit) gealfabetiseer word, word deur hulle voorgestel. Die voorstel is ten opsigte van uitdrukkings gemaak maar dit sou ook na ander meerwoordige leksikale items uitgebrei kon word. 'n Kernkomponent word as soekwoord of trefwoord gekies. Die soekwoord, gevolg deur 'n dubbelpunt, word vooraan die meerwoordige item geplaas en die geheel as lemma opgeneem. Hiervolgens sou die groepsetsel met behulp van soos volg gelemmatiseer kon word:

\section{behulp: met behulp van}

Die toekenning van leksikale-itemklassifikasies aan drie tipes multileksikale lemmas, t.w. uitdrukkings, groepsetsels en leenwoordgroepe word vervolgens bespreek.

\section{Uitdrukkings}

Uitdrukkings kan nie in terme van die tradisionele woordsoortklassifikasies benoem word nie, omdat hulle nie oor die vereiste sintaktiese of morfologiese eienskappe beskik nie. Uitdrukkings sou bloot op grond van hul vorm as sintaktiese konstruksies benoem kon word. Ponelis (1979: 5 e.v.) gebruik terme soos naamwoordstuk, adjektiefstuk, setselgroep en sin wat ook op uitdrukkings van toepassing gemaak sou kon word:

lyf en goed naamwoorstuk

lam in die knieë adjektiefstuk tot oorlopens toe setselgroep

sy lampie is uit sin

'n Uitdrukking is 'n naamwoordstuk, adjektiefstuk, setselgroep of sin wat tot 'n betekeniseenheid ontwikkel het en dit is onderworpe aan sekere semantiese, morfologiese en sintaktiese beperkings. Dit is derhalwe geen gewone sin of stuk of groep nie en die gebruiker gaan waarskynlik meer nut daarvan hê as dit bloot as uitdrukking geklassifiseer word.

'n Sekondêre klassifikasie van uitdrukkings kan egter gemaak word. Daar is woordgroepvakterme soos laminêre vloei en figuratiewe kuns en ook woordgroepe met 'n mindere mate van vakkundige betekenis soos van die liug haal en dic feite van die lewe wat ook as uitdrukkings kan kwalifiseer. Ons sou hierdie uitdrukkings gespesialiseerde uitdrukkings kon noem en die ander uitdrukkings idiomatiese uitdrukkings:

lawaaiwa: op die lawaaiwa klim idiomatiese uitdr.

lol: iemand 'n lol aandraai idiomatiese uitdr. 
laminêre: laminêre vloei gespesialiseerde uitdr.

feite: die feite van die lewe gespesialiseerde uitdr.

\section{Groepsetsels}

'n Groepsetsel, ook 'n groepvoorsetsel genoem, het betekeniseenheid, tree as geheel as setsel op, vervul dieselfde funksie as 'n simplekse voorsetsel en is ook dikwels vervangbaar daardeur: ten tyde van (tydens), met behulp van (met).

Groepsetsels is nie ' $n$ homogene groep nie, aangesien sommige semanties volkome deursigtig is soos in antwoord op, in samewerking met en ander nie, soos ten spyte van, ten behoewe van. Die ondeursigtige groepsetsels sou ook as uitdrukkings geklassifiseer kon word en Ponelis (1989: 49) gebruik dan ook die term setseluitdrukkings.

Die term groepsetsel kan verwarrend wees dangesien sirkumposisiesetsels soos tot ... toe in tot nou toe, deur ... heen in deur die jare heen ook as groepsetsels beskryf sou kon word. Die term groepvoorsetsel (Ponelis 1979: 173) is minder bekend, maar ook minder verwarrend aangesien dit soos die ander setselbenamings verwys na die plasing daarvan t.o.v. die aanvulling: voorsetsel, agtersetsel en sirkumposisiesetsel. Beide terme is waarskynlik aan die gemiddelde woordeboekgebruiker onbekend, maar omdat die term voorsetsel geen bekendstelling nodig het nie behoort woordeboekgebruikers nie probleme te hê met groepvoorsetsel as leksikale-itemklassifikasie nie:

spyte: ten spyte van groepvoorsetsel

gevolg: as gevolg van groepvoorsetsel

\section{Leenwoordgroepe}

'n Leenwoordgroep is ' $n$ woordgroep wat aan ' $n$ vreemde taal ontleen is en as 'n betekeniseenheid optree soos bona fide, laissez faire, sotto voce. Aangesien leenwoordgroepe in so 'n mate vir die gebruiker 'n eenheid vorm dat hy nie in staat is tot woordsoort- of kernkomponentonderskeiding nie, behoort dit ongemerk alfabeties, volgens die beginwoord, gelemmatiseer te word. Leenwoord-. groepe word in verklarende Afrikaanse woordeboeke as multileksikale lemmas opgeneem, maar word selde van 'n leksikale-itemklassifikasie voorsien:

in camera. (L.) ...

comme ci comme ça $(F$.$) ...(WAT)$

Die NW het verskillende hanteringswyses t.o.v. leenwoordgroepe en in sommige gevalle word 'n woordsoortklassifikasie verskaf:

lingua franca It. s.nw.

bona fides L. s.nw. 
carte blanche F. s.nw.

conditio sine qua non $L$.:

de novo L.:

curator ad litem $\mathrm{L}$.

In bogenoemde gevalle kan geredeneer word dat die sintaktiese optrede van die leenwoordgroepe telkens gelyk is aan dié van 'n leksikale lemma. Die eenheidskarakter van lingua franca word bv. ook daardeur geillustreer dat dit benewens die Latynse meervoud linguae francae ook 'n eiesoortige Afrikaanse meervoud het sonder die Latynse kongruensie van s.nw. en b.nw., nl. lingua francas. Die leenwoordgroep lingua franca se semantiese, morfologiese en sintaktiese optrede is dus dié van 'n eenheid en wel dié van 'n selfstandige naamwoord. Die hantering van lingua franca behoort in ooreenstemming met dié van ander selfstandige naamwoorde te wees:

lingua franca s.nw., lingua francas of soms linguae francae. (It.)

Alhoewel die Latynse leenwoordgroep bona fides 'n kongruente v roulike enkelvoudverbinding van b.nw. en s.nw. is, word dit in Afrikaans, waarskynlik na analogie van ander meervoudsuitgange op $-s$, as 'n meervoudsvorm gebruik met die betekenis van "goeie of opregte bedoelings". Sintakties, semanties en morfologies is dit ' $n$ eenheid wat optree soos ' $n$ selfstandige naamwoord.

Dit wil dus voorkom asof leenwoordgroepe 'n sterk woordkarakter het en in terme van die tradisionele woordsoortklassifikasies benoem kan word. Woordsoortaanduiding sal van groot nut wees omdat dit tesame met voorbeeldmateriaal die gebruiker in staat sal stel om die leenwoordgroep korrek te gebruik.

Verklarende Afrikaanse woordeboeke behoort hulle daarop toe te spits om op konsekwente wyse die gleuf vir leksikale-itemklassifikasie, bv. deur woordsoortaanduiding, in die artikels van leenwoordgroepe te vul.

\subsection{Tipiese sintaktiese optrede}

Inligting omtrent die tipiese sintaktiese optrede van 'n leksikale of multileksikale lemma kan in 'n tweede gleuf vir sintaktiese inligting verstrek word. Aangesien sintaktiese en morfologiese inligting die twee subtipes grammatiese inligting is, behoort dit opeenvolgend aangebied te word:

lus b.nw.; lusser, lusste. (slegs pred.)

lewensbelang s.nw. (gew. saam met van)

Inligting wat hier verstrek kan word, handel onder andere oor die tipiese voorsetselverbinding van sekere werkwoorde en selfstandige naamwoorde (voor- 
sien van, van lewensbelang), predikatiewe of attributiewe optrede van byvoeglike naamwoorde, die verbinding met 'n lidwoord (die meeste) en die passiewe of imperatiewe optrede van werkwoorde (gew. i.d. imperatief, gew. passief).

Inligting oor tipiese sintaktiese optrede kan ook by ' $n$ spesifieke betekenisonderskeiding verskaf word:

lel s.nw., lelle; lelletjie ...

3 (gew. saam met lang) lemand wat ...: So 'n lang lel het dit ook maar moeilik om klere te kry wat pas.

lees ww., het gelees ...

2 (saam met soos) Die indruk wek van: Die reeks gebeurtenisse wat gelei het tot die ontdekking van die skatte lees soos 'n speurverhaal.

3 (gew. in die imperatief) Vervang die voorafgaande deur: Die mense van Bavaria (lees: Beiere) is bekend vir hulle gemoedelikheid.

lekker b.nw.; lekkerder, lekkerste ...

3 (slegs i.d. negatief) Nie goed geluim of gesind nie: Haar kos was so smaaklik soos altyd, maar sy was nie lekker nie.

4 (slegs attributief) Joviaal en lief vir plesier: $H y$ is ' $n$ goeie tennisspeler en 'n lekker kêrel in die kroeg.

\subsection{Atipiese sintaktiese optrede}

In die derde gleuf vir sintaktiese inligting word voorbeeldmateriaal aangebied. Dit is nie die doel om hier 'n uitvoerige bespreking te gee omtrent die keuse van en ander aspekte van voorbeeldmateriaal nie (vgl. in hierdie verband Lombard 1992: 148-162). Voorbeeldmateriaal word veral gesien as ' $n$ implisiete weergawe van sintaktiese inligting (Gouws 1989: 229). Hierdie inligting kan egter deur middel van subgleuwe vir die gebruiker ontsluit word.

Die voorbeeldmateriaal illustreer die sintaktiese inligting wat in die ander twee gleuwe vermeld is. Inligting omtrent die atipiese asook ander sintaktiese optredes van 'n lemma wat vir die gebruiker van belang kan wees, kan egter op eksplisiete wyse in subgleuwe verstrek word. Ook die meerfunksionele optrede van 'n lemma kan in hierdie gleuf op eksplisiete wyse geïllustreer word. In die artikel van die werkwoord lees kan die volgende eksplisiete inligting onder meer verstrek word:

- Ook selfst.: Die praat, lees en skryf van ' $n$ taal.

- Met 'n persoon, bv. 'n skrywer, as direkte voorwerp: Hy lees graag Shakespeare.

- Met dit wat gelees word as onderwerp: Chaucer lees moeilik. Die boek lees lekker en hanteer maklik. 
'n Term wat met vrug in hierdie gleuf gebruik kan word, is dié van nabepaling (Ponelis 1979: 119), bv. in die artikels van die b.nwe. lekker en leersaam:

- As nabepaling: Selfs die terugstap was iets lekkers. Daar is niks lekkerders in die wêreld as om jou eie baas te wees nie. Daar is vir Jannie niks lekkerder as hierdie koel vogtige grond om in te speel nie.

- As nabepaling: Die lugoffisier het iets leersaams om mee te deel.

\section{Slotwoord}

Daar bestaan leemtes in die aanbieding van sintaktiese inligting in verklarende Afrikaanse woordeboeke. Die leemtes bestaan veral t.o.v. 'n konsekwente aanbieding van sintaktiese inligting by leksikale én multileksikale lemmas en t.o.v. die gebruik van nuwe inligting uit die teoretiese taalkunde. Die hoop word uitgespreek dat die voorstelle in hierdie artikel die praktiserende leksikograaf tot nut mag wees in die uitskakeling van die bestaande leemtes.

\section{Verwysings}

\section{Woordeboeke}

De Villiers, M. e.a. 1987. Nasionale Woordeboek. Kaapstad: Nasou.

Labuschagne, F.J. en Eksteen, L.C. 1993. Verklarende Afrikaanse Woordeboek. Pretoria: Van Schaik. Odendal, F.F. 19792. Verklarende Handwoordeboek van die Afrikanse Taal. Doornfontein: Perskor.

Schoonees, P.C.F.J. Snijman/D.C. Hauptfleisch (Reds.). 1950-1991. Woordeboek van die Afrikaantse Taal. Pretoria: Staatsdrukker/Stellenbosch: Buro van die WAT.

\section{Ander bronne}

Botha, T.J.R. (Red.). 1989. Leksikografie en leksikologie. Pretoria: Serva.

Botha, W.F. 1991. Die lemmatisering van uitdrukkings in verklarende Afrikaanse woordeboeke. Lexikos. AFRILEX-reeks 1: 1991: 20-36.

Gouws, R.H. 1989. Leksikografie. Kaapstad: Academica.

Gouws, R.H. 1990. Vaste uitdrukkings as multileksikale lemmas in verklarende Afrikaanse woordeboeke. Tydskrif vir Geesteswetenskappe 30(4): 265-283.

Lombard, F.J. 1992. Voorbeeldmateriaal in woordeboeke. Lexikos 2. AFRILEX-reeks 2: 1992: 148-164.

Otto, A.N. 1989. Kriteria vir 'n Afrikaanse aanleerderwoordeboek. Ongepubliseerde D.Litt.-verhandeling. Universiteit van Stellenbosch.

Ponelis, F.A. 1979. Afrikaanse sintaksis. Pretoria: Van Schaik.

Ponelis, F.A. 1989. Leksikale elemente. Botha, T.J.R. (Red.). 1989: 48-54.

Redaksie, Buro van die WAT. 1989. Nofule van die groepsgesprek wat oan 27 tot 29 November 1989 op Stellenbosch plaasgevind het. Ongepubliseerde verslag. Stellenbosch: Buro van die WAT.

Zgusta, L. 1971. Manual of Lexicography. Den Haag: Mouton. 